Inovação, Sustentabilidade e Pandemia

10 a 14 de maio de 2021

\title{
FATORES DIRECIONADORES (DRIVERS) DA INTERAÇÃO DE EMPRESAS COM UNIVERSIDADES: ESTUDO DE CASOS MULTIPLOS DE EMPRESAS-FILHAS DA UNIVERSIDADE ESTADUAL DE CAMPINAS (UNICAMP)
}

\author{
Vanessa Criscuolo Parreiras Oliveira (Instituto de Economia - IE/UNICAMP); \\ Renato de Castro Garcia (IE/UNICAMP); \\ Miguel Juan Bacic (IE/UNICAMP)
}

\section{resumo:}

Este trabalho investiga os fatores direcionadores (drivers) da interação de empresas-filhas da UNICAMP com a universidade. Para tanto, explora os resultados de seis estudos de caso exploratórios de relacionamentos cooperativos de empresas-filhas com a UNICAMP. São investigadas características estruturais e comportamentais das empresas investigadas, dos seus relacionamentos cooperativos com a universidade e da política de C\&T\&I que são conducentes ao desenvolvimento da cooperação entre as partes. Os resultados mostram que são diversas as variáveis que influenciam a propensão de empresas-filhas a cooperarem com a UNICAMP ao longo do tempo. A capacidade de absorção da firma, a existência de vínculos prévios e as proximidades geográfica e cognitiva entre as partes constituem importantes fatores direcionadores do estabelecimento e do desenvolvimento das cooperações das empresas investigadas com a universidade. Os estudos de caso mostram, ainda, a importância do acesso ao financiamento público para a cooperação, especialmente quando compreendem maior complexidade e risco.

palavras-chave:

fatores direcionadores (drivers); interação universidade-empresa; empresas-filhas

\section{Código JEL:}

O30; 039

Área Temática:

4.4 Redes de inovação - alianças de P\&D, interações universidade-empresa, outras redes 


\section{INTRODUÇÃO}

As universidades constituem uma fonte de conhecimento muito importante para os esforços inovativos das firmas, particularmente em indústrias nas quais os resultados da pesquisa acadêmica estão mais diretamente conectados à inovação industrial (KLEVORICK et al., 1995; MANSFIELD e LEE, 1996; MOWERY e SAMPAT, 2005). Os resultados (outputs) econômicos da pesquisa universitária incluem informações científicas e tecnológicas, que podem aumentar a eficiência da P\&D aplicada na indústria pela orientação da pesquisa em direções mais frutíferas; equipamentos e instrumentação usados por firmas em seus processos produtivos ou sua pesquisa; competências ( skills) ou capital humano incorporado em estudantes e membros de universidades; redes de capacitações (capabilities) científicas e tecnológicas, que facilitam a difusão de novos conhecimentos; e protótipos de novos produtos e processos (MOWERY e SAMPAT, 2005).

As universidades vêm crescentemente complementando suas atividades de ensino e pesquisa com atividades de uma terceira vertente orientada a um impacto socioeconômico (ETZKOWITZ et al., 2000; GEUNA e MUSCIO, 2009). Na economia do conhecimento, a universidade empreendedora contribui para o desenvolvimento econômico e social por meio de três missões simultâneas, o ensino, a pesquisa e o empreendedorismo (GUERRERO et al., 2015; URBANO e GUERRERO, 2013).

Segundo Etzkowitz et al. (2000), a emergência da universidade empreendedora (entrepreneurial university) pode ser apreendida como uma resposta à crescente importância do conhecimento nos sistemas nacionais e regionais de inovação e ao reconhecimento de que a universidade é um agente de transferência de conhecimento e tecnologia. As atividades empreendedoras são realizadas pelas universidades com o objetivo de contribuir para o desempenho econômico nacional e/ou regional; para que os cientistas se apropriem do valor de sua propriedade intelectual e tenham acesso a mecanismos de financiamento adicionais para promover sua agenda de pesquisa; bem como pela oportunidade de ter professores e alunos interagindo no nível aplicado com organizações de base tecnológica (BERCOVITZ e FELDMAN, 2006; ETZKOWITZ et al., 2000; LINK e SCOTT, 2005). A maior parte das atividades dessa terceira vertente se concentra em empresas spin-offs e mecanismos que vinculam a universidade e a indústria como, por exemplo, patentes conjuntas e licenciamento de patentes (CAMPOS, 2010).

As empresas spin offs universitárias são apreendidas como um produto da atividade relacionada à pesquisa universitária e um resultado dos esforços intencionais de transferência de tecnologia da universidade (LINK e SCOTT, 2005; D`ESTE e PATEL, 2007). Na literatura que aborda as interações entre a indústria e as organizações públicas de pesquisa as spin offs de universidades são identificadas como um modo ou canal de interação usado pelas firmas para explorar o conhecimento desenvolvido pela academia (ARZA et al., 2015; D`ESTE e PATEL, 2007). Nas empresas spin-offs, criadas a partir de pesquisa básica, os acadêmicos transferem suas habilidades, conhecimento tácito, resolução de problemas e habilidades diretamente em um ambiente comercial (SALTER e MARTIN, 2001). A academia pode também fornecer suporte e preencher outros tipos de funções para a spin off acadêmica também durante e após a etapa de comercialização (TREIBICH et al., 2013).

As incubadoras relacionadas à academia constituem um elo entre as inovações desenvolvidas por universidades ou faculdades e as firmas que as comercializam para o público em geral. Segundo Nowak e Grantham (2000), as incubadoras frequentemente trabalham conjuntamente com fundos e redes estaduais e regionais e são locais especialmente projetados para estimular o crescimento de startups, abordando sua falta de recursos físicos ou capital. As incubadoras fornecem às startups uma rede de suporte, infraestrutura e instalações físicas, aumentando a probabilidade de sucesso das empresas incubadas. Para spin offs acadêmicas e startups, a universidade pode servir como uma fonte de vantagem, fornecendo mão de obra qualificada e acesso a professores e alunos, instalações especializadas e expertise.

Alguns autores investigam os determinantes da formação de empresas spin-off universitárias (por exemplo, DI GREGORIO e SHANE, 2003; LINK e SCOTT, 2005; LOCKETT e WRIGHT, 2005; MUSCIO et al., 2016; SALTER e MARTIN, 2001) e a atividade regional de startups (MOTOYAMA e MALIZIA, 2017; vanSTIN et al., 2017). Pouca atenção foi dada na literatura, todavia, à caracterização da interação contínua entre essas empresas e as universidades de origem e à investigação do desenvolvimento dos seus relacionamentos cooperativos. Alguns estudos (por exemplo, LAAGE-HELLMAN et al., 2020; TREIBICH et al., 2013) investigam a natureza e a dinâmica da interação entre spin-offs acadêmicas e a academia. Esses autores identificam que a dinâmica do processo de interação é uma característica importante das relações entre esses agentes. Segundo Laage-Hellman et al. (2020), as spin offs universitárias continuariam a interagir com a academia no longo prazo, isto é, após ter alcançado o contexto empresarial. A dinâmica das interações é manifestada por meio de mudanças nos relacionamentos individuais e por adição/término de relacionamentos. Treibich et al. (2013) acrescentam que as trajetórias relacionais podem abranger padrões dinâmicos que 
abrangem desde a desconexão precoce de interações em linha com o modelo linear de inovações até interações sustentadas de suporte à produção conjunta de conhecimento. Alguns padrões dinâmicos podem incluir até mesmo uma alteração no modo de produção de conhecimento ao longo do tempo.

Um conjunto da literatura que aborda os relacionamentos cooperativos entre universidades e empresas identifica que são diversas as variáveis que influenciam a propensão das firmas a cooperar com universidades. Os estudos que analisam os fatores impulsionadores (drivers) da cooperação entre organizações públicas de pesquisa e a indústria, da perspectiva das firmas, identificam que fatores estruturais, comportamentais, geográficos e relacionados a políticas são os mais importantes impulsionadores destes relacionamentos cooperativos (DE FUENTES e DUTRENIT, 2012; OLIVEIRA et al., 2018).

É importante salientar que, apesar de haver uma ampla literatura que aborda os principais fatores direcionadores da interação U-E na perspectiva das firmas, há escassos trabalhos empíricos que abordam os drivers dos relacionamentos cooperativos de spin offs universitárias e startups com as universidades de origem ao longo do tempo (por exemplo, TREIBICH et al., 2013).São também pouco numerosos os trabalhos que abordam os relacionamentos U-E de longa duração (CAMPOS, 2010; GARCIA et al., 2019; MOTOYAMA, 2014). Particularmente a dinâmica de longo prazo das interações entre spin offs universitárias e startups e as universidades de origem permanece como uma importante lacuna na literatura, posto que o foco da maioria dos trabalhos reside nas fases iniciais do desenvolvimento de spin-off (alguns anos) (TREIBICH et al., 2013).

Este trabalho traz novos elementos para essa discussão, por meio da investigação dos fatores direcionadores (drivers) da interação de empresas-filhas da Universidade Estadual de Campinas (UNICAMP) com a universidade. As empresas-filhas possuem um dos seguintes tipos de vínculos com a universidade: a) seus fundadores são ex-alunos e alunos; b) seus fundadores são pessoas com vínculo empregatício vigente ou encerrado com a universidade (docentes ou funcionários); e c) são startups incubadas ou graduadas pela Incamp (Incubadora de Base Tecnológica da UNICAMP) (INOVA UNICAMP, 2020).

A UNICAMP atua como um elo central da rede formada pelos atores do Ecossistema Empreendedor da Região Metropolitana de Campinas, atuando como eixo estruturante na dinâmica dessas relações (GASPAROTO e FISCHER, 2020; SCHAEFFER et al., 2018). A importância da universidade para o ecossistema empreendedor se verifica através de seus institutos, departamentos e entidades estudantis e de suas empresas-filhas (GASPAROTO e FISCHER, 2020).

Para cumprir com este propósito, este trabalho explora os resultados de seis estudos de caso exploratórios de relacionamentos cooperativos da UNICAMP com empresas-filhas ${ }^{1}$. Desse modo, procura contribuir para a compreensão da natureza e do desenvolvimento da interação ao longo do tempo entre empresas que possuem vinculação com universidades (spin-offs universitárias e startups) e a academia. São investigadas características estruturais e comportamentais das empresas, dos seus relacionamentos cooperativos com a universidade e da política de $C \& T \& I$ que são conducentes à interação U-E na perspectiva do desenvolvimento da cooperação entre as partes.

O texto está organizado em cinco seções, incluindo esta introdução. A segunda seção apresenta uma breve revisão da literatura empírica sobre a cooperação U-E, com foco em alguns dos principais direcionadores (drivers) do envolvimento das empresas com essa cooperação. A terceira seção aborda os procedimentos metodológicos utilizados e o arcabouço analítico adotado na análise dos resultados. A quarta seção expõe a discussão dos resultados de pesquisa, seguida pelas considerações finais na quinta seção.

\section{OS FATORES DIRECIONADORES (DRIVERS) DA INTERAÇÃO ENTRE UNIVERSIDADES E INSTITUTOS PUBLICOS E EMPRESAS}

Na literatura neoschumpeteriana sobre inovação e cooperação há uma extensa pesquisa empírica que estuda o lado da demanda por vinculações entre firmas e organizações públicas de pesquisa. Vasta parcela dessa literatura enfoca os fatores direcionadores da interação, isto é, os drivers que influenciam os relacionamentos cooperativos das firmas com universidades e institutos públicos de pesquisa (IPPs).

Existem controvérsias no que se refere ao efeito do tamanho da firma sobre a probabilidade do seu engajamento na cooperação para a inovação. Segundo Tether (2002), por um lado, firmas novas e pequenas

\footnotetext{
${ }^{1}$ Os mecanismos da estratégia empreendedora da UNICAMP, que vão ao encontro do modelo de universidade empreendedora, são implementados por intermédio de sua Agência de Inovação (Inova). Eles incluem a criação de mecanismos cooperativos com o setor produtivo e outras instituições de ciência e tecnologia (ICTs); o estreitamento das relações U-E a partir de ambientes de cultura empreendedora; a proteção e comercialização da propriedade intelectual; a promoção de uma cultura inovadora na universidade; e o fortalecimento do ecossistema de empreendedorismo (ARBIX e CONSONI, 2010; BALDONI, 2014; GASPAROTO e FISCHER, 2018; INGLEZ et al., 2016; LEMOS, 2012).
} 
poderiam possuir maior necessidade de acordos cooperativos para a inovação, por que, de modo geral, elas possuem menos recursos internos. Por outro lado, as grandes firmas, ademais de possuírem mais recursos internos, são prováveis de se engajarem em uma gama mais ampla de atividades, incluindo algumas que poderiam se beneficiar da cooperação. Desse modo, o próprio tamanho da firma proporciona pouca orientação (se ou não) as firmas poderiam se engajar em arranjos cooperativos para a inovação.

Particularmente no que se refere à cooperação com universidades, a literatura salienta que, por um lado, as grandes firmas são capazes de dedicar maiores recursos e tempo à construção de vínculos com as universidades (FONTANA et al., 2003; CARDAMONE e PUPO, 2015), além de tenderem a possuir maior conhecimento das capacidades destas organizações orientadas à pesquisa (TETHER, 2002). As maiores firmas são mais propensas a possuir a capacidade para explorar fontes externas de conhecimento e para gerir interações com universidades, posto que são capazes de dedicar maiores recursos e tempo à construção de vínculos com universidades do que as pequenas firmas, que podem operar em um ambiente com recursos mais limitados (LAURSEN e SALTER, 2004). As grandes firmas são também mais propensas a empregar um staff com treinamento profissional em ciência e engenharia. Com tal background profissional, esses funcionários são capazes de se beneficiarem de suas relações com universidades para dar suporte ao trabalho na organização. Por outro lado, as firmas menores possuem menos recursos internos e necessitam de mais conhecimento externo para seus esforços inovativos, o que se traduz em maior número de parceiros cooperativos (FONTANA et al., 2003; CARDAMONE e PUPO, 2015).

Estudos que investigaram os fatores determinantes (drivers) da cooperação U-E, baseados em dados de países desenvolvidos, encontraram que o tamanho é positivamente relacionado à probabilidade de as firmas utilizarem o conhecimento de universidades e a cooperarem com elas (por exemplo, COHEN et al., 2002 e SANTORO e CHAKRABARTI, 2002, para os Estados Unidos); MOHNEN e HOAREAU (2003) para Alemanha, França, Irlanda e Espanha; FONTANA et al. (2003), para Dinamarca, França, Alemanha, Grécia, Itália, Holanda e Reino Unido; LAURSEN e SALTER (2004) para o Reino Unido; HANEL e ST-PIERRE (2006) para o Canadá; SCHARTINGER et al. (2001) para a Áustria; e CARDAMONE e PUPO (2015) para Alemanha, Itália, Espanha e Reino Unido). Os resultados destes trabalhos são consistentes com a hipótese de que a capacidade de as firmas utilizarem a pesquisa universitária aumenta com o tamanho da organização. Todavia, Torres et al. (2011) encontram para o México que, quanto maiores as firmas, menor é a sua propensão a se engajarem em interações U-E. Os dados dos autores sugerem que pequenas firmas, provavelmente com atividades intensivas em P\&D, crescentemente procuram acessar o conhecimento de universidades e IPPs. Resultados similares para as firmas da Malásia permitiram a Rasiah e Govindaraju (2009) argumentarem que a relação entre o tamanho e a colaboração com universidades e IPPs não é óbvia. No Brasil, Bastos e Britto (2017) constatam, a partir da Pesquisa de Inovação do Instituto Brasileiro de Geografia e Estatística (PINTEC/IBGE), que a variável porte tem importância no sentido de induzir a intensificação de relações cooperativas entre empresas inovativas nacionais e centros de produção científico-tecnológica.

No que tange especificamente às empresas startups, Cohen et al. (2002) identificam que as grandes firmas são mais propensas a utilizar a pesquisa pública do que as pequenas, à exceção das startups, que também fazem uso particular da pesquisa pública (especialmente na indústria farmacêutica). A esse respeito, sugerem que algumas startups são originadas em universidades e, então, têm fortes laços pré-existentes ou talvez sejam spinoffs de grandes firmas e, consequentemente, se beneficiem dos laços mais fortes que existem entre as firmas maiores e as instituições públicas de pesquisa. Por sua vez, Laursen e Salter (2004) encontram que a firma ser (ou não) uma startup faz pouca ou nenhuma diferença para a sua probabilidade de colaborar com universidades.

A literatura sobre inovação salienta a existência de uma considerável variação interindustrial na propensão das firmas a utilizar universidades. Firmas em setores caracterizados por elevados níveis de investimento em P\&D e em outras atividades científicas e tecnológicas têm uma maior propensão a utilizar as universidades (LAURSEN e SALTER, 2004), de modo que pertencer a um setor científico aumenta a propensão do estabelecimento de colaborações diretas em inovação com universidades e laboratórios governamentais (MOHNEN e HOAREAU, 2003). Cohen et al. (2002) sugerem que a pesquisa pública possui um impacto substancial sobre a $P \& D$ industrial em umas poucas indústrias, particularmente a farmacêutica, e é geralmente importante ao longo de um amplo segmento do setor manufatureiro. Schartinger et al. (2002) encontram no grupo de setores com elevadas taxas de $\mathrm{P} \& \mathrm{D}$ que somente os setores de $\mathrm{P} \& \mathrm{D}$, indústria química, manufatura de instrumentos e a produção de veículos encontram-se ente os dez setores com as maiores intensidades de interação U-E. Intensidades elevadas de interação podem ser observadas em setores manufatureiros mais orientados a recursos, tais como produção de energia, manufatura de metais básicos, manufatura de papel, construção e agricultura. No setor de serviços, as intensidades de interação U-E seguem um padrão, qual seja, elevadas intensidades nos serviços relacionados aos produtores (producer-related 
services), bancos, seguros e serviços de computação.

A habilidade de uma firma reconhecer o valor da nova informação externa, assimilá-la e aplicá-la a fins comerciais é crítica para suas capacidades inovativas (COHEN e LEVINTHAL, 1990). Sua capacidade de absorção é, em grande medida, uma função do nível de conhecimento anterior relacionado da firma. Cohen e Levinthal (1990) salientam que a capacidade de absorção da firma refere-se não somente à aquisição ou assimilação de informação, mas também à habilidade para explorá-la (exploit). Portanto, a capacidade de absorção de uma firma não depende simplesmente da interface direta da organização com o ambiente externo. Ela depende também das transferências de conhecimento entre e dentro de subunidades. Segundo estes autores, a capacidade de absorção da firma depende dos indivíduos que permanecem na interface da firma e do ambiente externo ou na interface entre subunidades no interior da firma. A função de interface pode ser difundida entre indivíduos ou bastante centralizada. Quando a expertise da maioria dos indivíduos na organização difere consideravelmente daquelas dos atores externos que proporcionam informação útil, alguns membros dos grupos são prováveis de assumir papeis relativamente centralizados de gatekeeping"2 ou "boundary-spanning" (COHEN e LEVINTHAL, 1990).

Uma corrente da literatura investigou o impacto da capacidade de absorção da empresa sobre a cooperação U-E e identificou que a falta de capacidade de absorção pode constituir uma significativa barreira ao relacionamento cooperativo. Alguns autores salientam a importância da capacidade de absorção das empresas como um fator influente na busca pela parceria U-E e na apropriação dos benefícios dessa interação. Uma alta capacidade de absorção - potencial e realizada - faz que com a firma esteja mais apta a transformar conhecimentos externos em novos produtos e processos produtivos, com efeitos importantes em seu desempenho inovativo (ROSA et al., 2018). A realização de investimentos em P\&D amplia a capacidade de absorção de conhecimentos da firma e, por essa razão, elas tendem a valorizar mais as universidades como fonte de informação (ALBUQUERQUE et al., 2005). As firmas com empregados altamente qualificados são as que mais colaboram com universidades (BRUNEEL et al., 2010; LAURSEN et al., 2011; GARCIA et al., 2015; DREJER e ØSTERGAARD, 2017).

Em relação aos determinantes das dimensões da capacidade de absorção, a capacidade de adquirir o conhecimento externo não está relacionada com a atividade de P\&D interna (TEIXEIRA et al., 2016), visto que se relaciona ao predomínio de trabalhadores com pós-graduação, que podem agir como gatekeepers do conhecimento, facilitando a identificação e a aquisição desse conhecimento na ausência de esforços mais estruturados de P\&D na empresa.

Alguns autores exploraram o impacto da experiência prévia da firma em trabalhar em projetos de pesquisa com universidades sobre os relacionamentos cooperativo U-E. Segundo Cyert e Goodman (1997), esses relacionamentos constituem uma oportunidade para o aprendizado, que pode impactar o pensamento estratégico da organização, a cultura, as habilidades para resolução de problemas e a base de conhecimento. Para a corporação, a mudança organizacional relacionada ao relacionamento cooperativo com universidades pode se verificar em termos de novos produtos, políticas de aplicação ou práticas. Bruneel et al. (2010) observam que trabalhar com universidades em projetos de pesquisa requer não somente que as firmas aprendam a trabalhar em fronteiras organizacionais (organizational boundaries), mas também requer que elas tenham ou possam construir as capacidades (capabilities) para colaborar com parceiros que operam em um sistema de incentivo diferente. A colaboração com um parceiro de universidade necessita que as firmas desenvolvam rotinas e práticas operacionais para gerir esta colaboração. Entretanto, uma vez que as rotinas e práticas tenham sido estabelecidas, elas são prováveis de serem refinadas e reutilizadas em colaborações subsequentes. Ainda segundo os autores, a experiência em colaboração poderia auxiliar também a reduzir as barreiras à colaboração relacionadas à transação.

A pesquisa recente enfoca também o papel da proximidade geográfica entre as firmas e organizações públicas de pesquisa (por exemplo, ARUNDEL e GEUNA, 2004; BRÖSTROM, 2010; CAMPOS, 2010) e dos demais tipos de proximidades (D`ESTE et al., 2013; GARCIA et al., 2018; DREJER e ØSTERGAARD, 2017). A existência de transbordamentos locais de conhecimento (geographlically bounded spillovers) da universidade para as empresas (MANSFIELD e LEE, 1996; ARUNDEL e GEUNA, 2004; LAURSEN et al., 2011; GARCIA et al., 2013, SALTER e MARTIN, 2001, entre outros) se soma às maiores possibilidades de interação associada à proximidade geográfica. A proximidade geográfica entre empresas e universidades facilita a interação entre os pesquisadores acadêmicos e os cientistas e engenheiros responsáveis pelo P\&D nas

\footnotetext{
${ }^{2}$ Segundo Allen (1977), os gatekeepers, isto é, os indivíduos que conectam suas organizações ao ambiente externo: 1) constituem uma pequena comunidade de indivíduos; 2) estão no núcleo (core) de uma rede de informações; 3 ) são demasiadamente expostos a fontes externas de informação; e; 4) possuem vínculos com atores externos principalmente informais.
} 
empresas, posto que que permite interações frequentes, contatos pessoais e interação face a face. Tais mecanismos favorecem os processos de aprendizado interativo entre os agentes (GARCIA, 2017). A esse respeito, Link e Scott (2005) encontram que as empresas spin-offs estão mais concentradas em parques que estão geograficamente mais próximos de sua universidade.

A noção de proximidade cognitiva implica que as firmas que compartilham a mesma base de conhecimento e as mesmas habilidades são capazes de estabelecer processos de aprendizado interativo entre elas (KNOBEN e OELERMANS, 2006; BOSCHMA, 2005; GARCIA, 2017). As firmas buscam novo conhecimento em grande proximidade à sua base de conhecimento existente, o que proporciona oportunidades e define as limitações para melhorias adicionais. A distância cognitiva não deve ser demasiadamente elevada, visto que a capacidade de os atores ou firmas absorverem novo conhecimento requer proximidade cognitiva, ou seja, sua própria base cognitiva deve ser próxima o suficiente ao novo conhecimento com a finalidade de comunicar, entender e processá-lo com sucesso (BOSCHMA, 2005).

A proximidade cognitiva pode substituir a geográfica na colaboração U-E, já que a capacidade e a expertise compartilhadas entre a firma que colabora e o parceiro acadêmico estimulam uma colaboração a longa distância (GARCIA et al., 2016). As relações direcionadas pelos empregados (medidas pelo local de qualificação e sua disciplina científica) e pelos altos gerentes influenciam fortemente a probabilidade de que as firmas colaborem com universidades específicas (DREJER; ØSTERGAARD, 2017). Esse resultado confirma a existência de efeitos separados e sobrepostos das relações direcionadas pelos empregados e da proximidade geográfica.

As relações pessoais permitem que pessoas-chave se conheçam, gostem e confiem umas nas outras e criem laços sociais que apoiam a interação entre a spin-off acadêmica e seus parceiros (LAAGE-HELLMAN et al., 2020). Conforme esses autores, a força dos vínculos relacionais entre spin offs acadêmicas e a universidades e laços é de grande importância para a forma como a interação se desenvolve e os pré-requisitos para a criação de uma colaboração frutífera. Os vínculos e laços são criados e fortalecidos por meio da interação, mas dependendo de como a interação se desdobra, eles podem se tornar mais fracos e, eventualmente, até deixar de existir.

Os fatores relacionados às políticas de C\&T\&I e industrial (iniciativas governamentais para a intensificação de práticas cooperativas das firmas com a infraestrutura de C\&T e financiamento público) incluem incubadoras de negócios (NOWAK e GRANTHAM, 2000), a promoção de clusters inovativos industriais (SOHN e KENNEY, 2007) e a iniciação de projetos de pesquisa conjuntos. Além disso, o apoio do governo às firmas como um fator encorajador à colaboração com universidades foi identificado em alguns trabalhos (por exemplo, DE FUENTES e DUTRENIT, 2012; MOHNEN e HOAREAU, 2003; FONTANA et al., 2003; OLIVEIRA et al., 2018)

Diferentes padrões de apoio financeiro influenciam o estabelecimento e a frequência das colaborações U-E (DE FUENTES e DUTRENIT, 2012). O apoio governamental aumenta a incidência de exploração de conhecimento de universidades/laboratórios governamentais e o estabelecimento de colaborações diretas em inovação com eles (MOHNEN e HOAREAU, 2003). A natureza do financiamento da cooperação parece interferir nos objetivos (ou na motivação) da cooperação U-E (RAPINI et al., 2014). Dessa forma, o financiamento exclusivo com recursos privados esteve mais voltado a resultados que contribuem diretamente na solução dos problemas da empresa e que são de maior apropriação (testes para produtos e processos; transferência de tecnologia), já a composição de recursos públicos e privados está vinculada a projetos cooperativos de maiores risco e custo (projetos em conjunto).

\section{METODOLOGIA}

Este trabalho utilizou o método de estudos de caso exploratórios com a finalidade de elucidar os fatores direcionadores (drivers) da interação de empresas-filhas da UNICAMP com a universidade. Trata-se de um estudo descritivo-explicativo de abordagem qualitativa, cujos meios de investigação utilizados foram a pesquisa bibliográfica e documental e o levantamento de campo.

Foram selecionadas para investigação detalhada seis empresas-filhas da UNICAMP de diferentes setores de atividade econômica e porte ${ }^{3}$. As informações utilizadas nos estudos de caso são provenientes de diferentes fontes. Primeiramente foi realizado um amplo levantamento de informações sobre as empresas pesquisadas e os seus respectivos fundadores nas plataformas Lattes e LinkedIn, no Diretório dos Grupos de

\footnotetext{
${ }^{3}$ Segundo a Inova (INOVA UNICAMP, 2011), no ano de 2020, o mapeamento das empresas-filhas da UNICAMP identificou 929 empresas ativas, sendo 55 delas consideradas empresas spin-offs. Essas empresas de base tecnológica foram criadas a partir de tecnologias resultantes de pesquisa desenvolvida na universidade, sendo elas protegidas ou não.
} 
Pesquisa no Brasil (DGP) do CNPq, na imprensa especializada e em sítios corporativos, da Inova e de agências de financiamento das atividades de C\&T\&I.

A pesquisa de campo foi conduzida entre os anos de 2015 e 2020. As seis empresas selecionadas, caracterizadas a seguir, foram objeto de visitas, oportunidades em que foram realizadas entrevistas semiestruturadas com cofundadores - Chief Executive Officers (CEOs), Chief Technology Officers (CTOs) ou cientistas-chefe - ou ainda gestores responsáveis pela área de PD\&I ou que relacionem com essas atividades. Foram realizadas também entrevistas semiestruturadas com quatro pesquisadores da universidade com os quais as empresas estabeleceram relacionamentos cooperativos. Adicionalmente, foram consideradas as evidências de documentos, publicações e observações da pesquisa de campo.

\subsection{Empresas selecionadas}

\subsubsection{Griaule}

A Griaule é uma pequena empresa que atua no desenvolvimento e licenciamento de programas de computador não-customizáveis. É especializada em tecnologias biométricas, notadamente no reconhecimento de impressões faciais e digitais para uso em aplicações convencionais ou na segurança pública.

A opção estratégica da empresa é basear seus negócios no desenvolvimento de softwares e na venda para distribuidores; para isso, desenvolve componentes de softwares para organizações que os integram a um produto, chamadas empresas integradoras (por exemplo, Diebold e Oracle), responsáveis por formatar o produto de acordo com as necessidades de seus clientes: pequenos estabelecimentos, grandes corporações e governos. É caracterizada como uma empresa multinacional born global brasileira (RIBEIRO e PIMENTEL, 2011; FLEURY e FLEURY, 2012).

A Griaule foi criada na Incamp, incubadora da UNICAMP, no ano de 2002, tendo saído do período de incubação em 2005. Encontra-se localizada em nas proximidades do campus da universidade. Segundo o CEO e cientista-chefe, na fase de incubação, a empresa obteve acesso à estrutura da UNICAMP, notadamente a pesquisadores altamente qualificados e à oportunidade de capacitação para o empreendedorismo e para a gestão de empresas.

A Griaule possui fortes vínculos com a UNICAMP. No período pós-incubação, os principais canais de transferência de conhecimento são a contratação de recém-graduados e pós-graduados, e a troca informal de informações entre os recursos humanos da empresa alocados no departamento interno de P\&D e seus exprofessores da Faculdade de Engenharia Elétrica e de Computação (FEEC).

\subsubsection{BioBrasil Biotecnologia}

A Bio Brasil Biotecnologia (atual Bio Brasil Ciência e Tecnologia) é uma fabricante de materiais para medicina e odontologia de pequeno porte. Foi fundada no ano de 2009, no Polo Industrial de Anápolis (Goiás) e possui uma unidade em Vinhedo, na região metropolitana de Campinas.

Para iniciar suas atividades, a empresa assumiu a produção e comercialização do TF-TEST (Three Fecal Test), kit para exame coproparasitológico desenvolvido por pesquisadores da UNICAMP e da Universidade de São Paulo (USP), em parceria com uma empresa adquirida (Immunoassay Indústria e Comércio) ${ }^{4}$. O desenvolvimento do TF Test compreendeu, no início da década de 2000, uma cooperação científica multidisciplinar com três pesquisadores (um da USP e dois da UNICAMP), que idealizaram e desenharam um kit para o diagnóstico de parasitoses gastrointestinais de humanos em amostras fecais (GOMES et al., 2008). Os pesquisadores perceberam a importância de atrelar as áreas de Biologia, Ciência da Computação, Ciências Farmacêuticas e Engenharia Industrial para desenvolvimento desse sistema por análise computadorizada de imagens e de seu uso, intitulado DAPI - Diagnóstico Automatizado de Parasitos Intestinais

\footnotetext{
${ }^{4}$ Vale destacar, nesse ponto, uma questão do relacionamento cooperativo entre a Immunoassay Indústria e Comércio, empresa que seria posteriormente incorporada pela Bio Brasil Biotecnologia, e a UNICAMP. A ImmunoCamp Pesquisa e Desenvolvimento de Tecnologia, que atuava no ramo da P\&D de tecnologia para produtos médico hospitalares, prestava assessoria científica de técnicas laboratoriais para hospitais, clínicas e laboratórios, além de realização de testes e exames laboratoriais em geral, foi constituída em fevereiro de 2010, tendo como sócia controladora a Immunoassay Indústria e Comércio (INOVA UNICAMP, 2011). A ImmunoCamp Pesquisa e Desenvolvimento de Tecnologia esteve incubada na Incamp e constituía, segundo um entrevistado, "um braço de pesquisa" da Immunoassay Indústria e Comércio, ao se dedicar exclusivamente às atividades de pesquisa. Nesse caso, a opção estratégica da Immunoassay Indústria e Comercio foi a de incubar a ImmunoCamp Pesquisa e Desenvolvimento de Tecnologia na incubadora da UNICAMP para que ela usufruísse da infraestrutura da universidade.
} 
(INOVA UNICAMP, 2011). Por meio desse novo sistema de diagnóstico, o computador obtém detecção automática de parasitos intestinais (ALVES-FILHO, 2007). Os resultados do TF-Test são inovadores, pois a tecnologia é abrangente para todas as espécies parasitárias (helmintos e protozoários), podendo substituir com diversas vantagens as técnicas convencionais e kits comerciais.

A opção estratégica da Bio Brasil Biotecnologia foi a da externalização de suas atividades de P\&D para a UNICAMP. A empresa formalizou a licença para exploração da tecnologia, em caráter exclusivo, para produção e comercialização de sistema para diagnóstico de parasitos intestinais de humanos por análise computadorizada de imagens, em área geográfica irrestrita, oriundos da tecnologia. Além de explorar comercialmente a referida nova tecnologia, a empresa coopera com a UNICAMP em novos projetos de desenvolvimentos conjuntos com o Instituto de Computação (IC).

\subsubsection{Padtec}

A Padtec, é uma média empresa voltada ao desenvolvimento, fabricação e comercialização de sistemas de comunicações ópticas. Trata-se de produtos de alta tecnologia para transmissão de dados em redes de fibra óptica. Os sistemas de comunicações ópticas baseados na tecnologia DWDM (Dense Wavelength Division Multiplexing), utilizados no núcleo da rede, possuem aplicações em redes de entroncamento, como de longa distância, metropolitanas ou de conexões ponto a ponto em redes de armazenamento. É a única empresa no hemisfério sul desenvolvedora de tecnologia DWDM.

A Padtec foi constituída no ano de 1999, em Campinas, como uma unidade da Fundação CPqD Centro de Pesquisa e Desenvolvimento em Telecomunicações (Fundação CPqD) e se tornou uma empresa independente em 2001. A Padtec encontra-se localizada no Parque II do Polo de Alta Tecnologia de Campinas, nas proximidades do $\mathrm{CPqD}$. A empresa teve como cofundadores dois ex-alunos (de graduação e pósgraduação) da UNICAMP.

A Padtec caracteriza-se por realizar esforços importantes em inovação tecnológica e, em especial, em P\&D. Com a finalidade de se manter na vanguarda da tecnologia e ofertar soluções de elevado valor agregado, fomenta, por meio de convênios, atividades de P\&D por meio de centros de excelência em comunicações ópticas. Dois centros bastante reconhecidos em comunicações ópticas - o CPqD e a UNICAMP -, realizam, em parceria, os trabalhos de desenvolvimento tecnológico mais próximos à fronteira do conhecimento e, portanto, sujeitos a maior risco (PADTEC, 2017).

A UNICAMP é uma importante instituição parceira e já possui com a empresa um longo histórico de relacionamentos. Os relacionamentos cooperativos enfocam projetos de pesquisa aplicada, voltados ao desenvolvimento de produtos, transferência de tecnologia desenvolvida pelo parceiro, contratação de recémgraduados e pós-graduados e troca informal de informações e envolveram, ao longo do tempo, diferentes grupos de pesquisa da universidade na FEEC e no Instituto de Física "Gleb Wataghin" (IFGW).

\subsubsection{Quinto Andar}

A QuintoAndar é uma imobiliária digital, cujo negócio é focado em aluguel de casas e apartamentos residenciais. Seu principal produto é um aplicativo para aluguel de apartamentos (LAVCA, 2019). Recentemente, começou a atuar com compra e venda de imóveis. Iniciou suas atividades no ano de 2013, em Campinas, e teve como cofundador um ex-aluno (de graduação e pós-graduação) do IC da UNICAMP. Embora a empresa tenha transferido sua sede para São Paulo no ano de 2015, recentemente reabriu um centro de engenharia e produto em Campinas, que trabalha de maneira integrada aos times de São Paulo.

Atuando em um setor tradicional, a plataforma imobiliária digital QuintoAndar é o maior player de aluguéis da América Latina A tecnologia imobiliária da QuintoAndar configura uma disrupção no modo como o mercado imobiliário funciona no Brasil. Em sua estrutura organizacional, os times interdisciplinares de tecnologia e produto desempenham um papel central no modelo de negócio. Segundo o cofundador e CTO, os recursos humanos da empresa dedicam-se continuamente à resolução de problemas estratégicos nos processos de locação e intermediação de imóveis e, para tanto, fazem uso intensivo de ferramentas, como inteligência artificial e learning machine, e design. Há, dessa forma, um aprimoramento contínuo de produtos e serviços.

A contratação de recém-graduados e pós-graduados, particularmente no escritório de tecnologia de Campinas, é o principal canal de interação com a UNICAMP. A QuintoAndar possui também programas de estágios para alunos de graduação e de financiamento de bolsas de pós-graduação no IC.

\subsubsection{GranBio}


A GranBio é uma média empresa de biotecnologia industrial, criada com o objetivo de desenvolver biocombustíveis de segunda geração e bioquímicos. Fundada em 2011, em São Paulo, a empresa teve como cofundador e cientista-chefe no período de 2012 a 2016 um professor do IB/UNICAMP.

A empresa produz etanol celulósico ou etanol de segunda geração $(2 \mathrm{G})$, a partir de coprodutos da canade-açúcar - palha e bagaço Trata-se de uma empresa inovadora, que alcançou importantes desenvolvimentos científicos e tecnológicos na produção do etanol de segunda geração, não se restringindo à utilização de tecnologias externas e licenciamentos de equipamentos e tecnologias de terceiros (ANGELI e VARRICHIO, 2017; CALIL NETO et al., 2018; FURTADO et al., 2020).

A BioCelere, subsidiária de pesquisa científica voltada para a conversão de biomassa em açúcar e desenvolvimento de microrganismos geneticamente modificados, instalou seu Centro de P\&D no TechnoPark, próximo à UNICAMP e ao Laboratório Nacional de Ciência e Tecnologia do Bioetanol (atual Laboratório Nacional de Biorrenováveis LNBR). Nessas instituições pode encontrar importantes competências relacionadas às biotecnologias aplicadas ao processo industrial (FURTADO et al., 2020).

A GranBio estabeleceu ao longo do tempo com o Instituto de Biologia (IB) da UNICAMP relacionamentos de tipo pesquisa científica, transferência de tecnologia desenvolvida pelo parceiro, contratação de recém-graduados e pós-graduados e troca informal de informações.

\subsubsection{Movile}

A Movile é um ecossistema de empresas de tecnologia de grande porte. Nasceu, no ano de 1998, na incubadora de empresas juniores da UNICAMP, em Campinas (MOVILE, 2019) e teve como cofundadores dois ex-alunos de graduação do IC da universidade.

A empresa iniciou suas operações desenvolvendo conteúdo para telefone celular e, no decorrer de sua trajetória, expandiu-se para outros setores de mercado. Tornou-se um grupo de conteúdo e serviços móveis com liderança na América Latina. É apontada como um exemplo de como uma pequena empresa empreendedora pode se desenvolver como um player global (BRITO e CARVALHO, 2018).

Alguns autores (BRITO e CARVALHO, 2018; PLAIS, 2016; MORGAN et al., 2015) notam que a inovação é parte da cultura organizacional da Movile desde a sua concepção e constitui um dos seus pilares estratégicos. O desenvolvimento de produtos inovadores e os movimentos de fusão e aquisição, com complementaridades de produtos e exploração de sinergias estratégicas (PLAIS, 2016), se encontram no cerne da expansão do Grupo em diferentes mercados. Dessa forma, na atualidade, a Movile é formada tanto por empresas que nasceram no interior do Grupo (PlayKids, Wavy e Movile Pay) quanto por empresas investidas em seu portfolio, como iFood, Sympla e Zoop. As empresas de serviços de tecnologia do Grupo Movile fazem uso intensivo de inovações e inteligência artificial no tratamento de informações e na resolução de problemas.

O recrutamento de recursos humanos (recém-graduados e pós-graduados) em programas de estágio e novos talentos é o principal canal de interação presente no relacionamento com a UNICAMP. Ademais, o CEO já ocupou a posição de presidente do UNICAMP Ventures, rede de relacionamento e colaboração formada por empreendedores ligados à universidade.

\subsection{Os fatores direcionadores da interação de empresas-filhas com a UNICAMP: um arcabouço analítico}

$\mathrm{O}$ arcabouço analítico adotado baseia-se em um conjunto de fatores estruturais, comportamentais, geográficos e relacionados a políticas apontados pela literatura como direcionadores (drivers) do estabelecimento e desenvolvimento de relacionamentos cooperativos U-E.

1. Setor de atividade econômica. Segundo a literatura empírica, há significativas diferenças interindústrias na intensidade das interações U-E. Na investigação de como os setores de atividades econômica influenciam o envolvimento das empresas-filhas com a interação com a universidade, essas empresas foram classificados conforme taxonomias de padrões setoriais de inovação de Campos e Ruiz (2009) para os quatro primeiros tipos de empresas industriais classificadas e Freire (2006) e Kubota (2009) para a classificação dos knowledge-intensive business services (KIBs).

2. A capacidade de absorção da firma. A literatura identifica que a qualificação da mão de obra e as atividades internas de $\mathrm{P} \& \mathrm{D}$ são importantes determinantes da capacidade de absorção da firma. Na investigação dessa capacidade nas empresas pesquisadas, este trabalho examinou suas atividades inovativas (atividades internas de $\mathrm{P} \& \mathrm{D}$ e aquisição externa de $\mathrm{P} \& \mathrm{D}$ e de outros conhecimentos externos) e a qualificação da sua mão de obra.

3. A existência de vínculos (links) prévios entre as partes. Vínculos prévios podem ser definidos 
quando, no passado, houve alguma colaboração em atividades similares ou aos parceiros colaborarem previamente em outras ocasiões (MORA-VALENTIN et al. 2004). Para investigar se a existência de vínculos prévios entre as empresas investigadas e a UNICAMP constituiu um fator direcionador da interação U-E, verificou-se, particularmente, se havia vínculos prévios dos indivíduos-chave no estabelecimento da interação com pesquisadores das respectivas universidades, bem como a natureza dessas conexões.

4. O acesso ao financiamento público e a concessão de benefícios fiscais. Neste trabalho, analisou-se o impacto do acesso das empresas-filhas a diferentes instrumentos de financiamento público no estabelecimento da interação U-E. Além disso, foram investigados os impactos da concessão dos benefícios fiscais, sobretudo no âmbito da Lei de Informática.

5. A proximidade geográfica e proximidade cognitiva entre os agentes. Na investigação do papel desempenhado pelas proximidades geográfica e cognitiva entre os agentes no estabelecimento e no desenvolvimento da interação U-E, foram tomadas como referência, primeiramente, as distâncias geográficas em linha reta entre as seis empresas-filhas e as faculdades ou institutos da universidade com os quais elas estabeleceram relacionamentos cooperativos. Em segundo lugar, procurou-se identificar a existência de um background disciplinar comum, isto é, uma base de conhecimento compartilhada pelos agentes envolvidos na interação.

\section{DISCUSSÃO DOS RESULTADOS}

\subsection{Setor de atividade}

O setor de atividade econômica constitui um importante fator direcionador (driver) dos relacionamentos cooperativos das empresas-filhas da UNICAMP com a universidade ao longo do tempo, conformando os canais de interação adotados e a intensidade da interação. Três empresas são oriundas de setores industriais que, conforme a literatura, contam mais fortemente com a pesquisa universitária. A Padtec se insere na categoria de setores baseados em ciência e intensivos em $P \& D$ e apresenta uma elevada intensidade de relacionamentos cooperativos $\mathrm{U}_{-} \mathrm{E}^{5}$. As indústrias baseadas em ciência (e, entre elas, as firmas do setor de fabricação de equipamentos transmissores de comunicação, peças e acessórios) apoiam-se particularmente no novo conhecimento científico e devem mostrar interações mais intensas com universidades (por exemplo, SCHARTINGER et al. 2002; LAURSEN et al., 2011).

Da mesma forma, a Bio Brasil Biotecnologia é uma fornecedora especializada e se apoia nos relacionamentos cooperativos com a UNICAMP de longa duração para suas operações. Firmas do setor de fabricação de materiais para medicina e odontologia encontram-se entre aquelas que interagem com uma ampla gama de campos da ciência e são geralmente mais propensas a colaborar com universidades (SCHARTINGER et al, 2002; LAURSEN et al, 2011).

A GranBio é uma fabricante de biocombustíveis, o que a aproximaria das firmas dos chamados setores industriais dominados por fornecedores. Os elementos utilizados pela GranBio para superar as barreiras à produção de bioetanol de segunda geração em escala comercial compreendem, contudo, o desenvolvimento interno de tecnologias e a capacidade de licenciá-las mundialmente (ANGELI e VARRICHIO, 2017; CALIL NETO et al., 2018). Os investimentos da empresa envolveram a montagem de uma infraestrutura de P\&D na subsidiária BioCelere; o desenvolvimento de novos produtos ou aperfeiçoamento de processos; a aquisição de patentes complementares; e a construção de uma rede de parcerias tecnológicas e a elaboração de diversos projetos de P\&D interno e externo, seguindo um modelo de inovação aberta ${ }^{6}$ (ANGELI e VARRICHIO, 2017; CALIL NETO et al., 2018), na qual a UNICAMP foi um ator central.

As empresas Griaule, QuintoAndar e Movile são empresas de serviços fortemente baseadas em tecnologia. A Griaule e a Movile são empresas que se enquadram nos denominados knowledge-intensive business services (KIBs) os quais, segundo a literatura (por exemplo, SCHARTINGER et al., 2002; MILES, 2007 e HIPP e GRUPP, 2005), apresentam fortes vínculos com a base científica. Por sua vez, embora a QuintoAndar atue em um setor tradicionalmente pouco inovador (serviços imobiliários), trata-se de uma

\footnotetext{
${ }^{5}$ A empresa estabeleceu relacionamentos cooperativos com grupos de pesquisa das seguintes universidades e institutos de pesquisa: CPqD; Universidade Federal de Pernambuco - UFPE; Universidade Federal de Itajubá - UNIFEI; UNICAMP; Universidade Estadual de Ceará - UECE; Centro Nacional de Pesquisa em Energia e Materiais - CNPEM; Universidade Estadual Paulista Júlio de Mesquita Filho - UNESP e Instituto Atlântico.

${ }^{6}$ Essa rede incluiu parcerias estratégicas com algumas das principais empresas do segmento e projetos de P\&D com instituições de ciência e tecnologia (UNICAMP, UFAL - Universidade Federal do Alagoas, IAC - Instituto Agronômico de Campinas e USP na perspectiva de um modelo de gestão da inovação aberta (ANGELI e VARRICHIO, 2017; CALIL NETO et al., 2018).
} 
empresa de tecnologia que, diferentemente das plataformas de listagem de imóveis, opera como uma corretora digital de "ponta a ponta" no processo de locação.

Essas três últimas empresas estabeleceram relacionamentos ao longo do tempo com a UNICAMP baseados essencialmente na contratação de recursos humanos (ex-alunos de graduação e pós-graduação). A esse respeito, vale notar que nos KIBs profissionais as estratégias de resolução de problemas são restringidas em uma variedade de modos pelas capacidades dos funcionários e também dos clientes (CONSOLI e ELCHEHORTELANO, 2010). No caso da Griaule, há também trocas informais de informação entre as partes, direcionadas pelas proximidades geográfica e cognitiva entre as partes.

\subsection{A capacidade de absorção da firma}

Os estudos de caso permitiram identificar que as atividades internas de $\mathrm{P} \& \mathrm{D}$ e a qualificação da mão de obra de cinco empresas-filhas da UNICAMP pesquisadas favorecem o desenvolvimento da sua capacidade de absorção. Essas empresas realizam atividades internas de P\&D ou desenvolvimento/ tecnologia formais e contínuas. Ademais, são também caracterizadas pela significativa participação de profissionais com nível superior ou mais no conjunto dos seus recursos humanos alocados nessas atividades. As atividades internas de $\mathrm{P} \& \mathrm{D}$ ou de desenvolvimento/tecnologia dessas empresas foram caracterizadas pelos entrevistados como "importante" para que inovem (em produto e em processo). Dessa forma, criam-se as condições requeridas para o desenvolvimento das interações com a UNICAMP ao longo do tempo.

A Padtec realiza consistentes esforços de busca de conhecimento externo para assimilá-lo (inclusive de fontes de conhecimento externas localizadas no exterior) e incorporá-lo aos seus produtos. A pesquisa de campo identificou que suas atividades internas de P\&D em comunicações ópticas são contínuas e eram conduzidas por uma equipe que era composta por 90 profissionais de nível superior em dedicação exclusiva. Essa equipe era formada principalmente por engenheiros elétricos e de computação $(15,1 \%$ dos recursos humanos), físicos e graduados em ciência da computação. A participação de pós-graduados (mestres e doutores) na Diretoria de Tecnologia da empresa varia historicamente entre 35 e $40 \%$. Além dos esforços internos de P\&D, a Padtec Submarine, unidade de negócios da empresa voltada para comunicação óptica por cabos submarinos, é composta por uma equipe de pesquisadores/desenvolvedores na Itália e um back office no Brasil (PADTEC, 2017). A unidade italiana é contemplada por consultores com notório conhecimento em comunicações ópticas submarinas, contratados para atuarem no desenvolvimento de equipamentos ${ }^{7}$. Os dispêndios totais em P\&D alcançam o patamar de aproximadamente 15\% do faturamento anual da empresa, percentual mantido estável ao longo do tempo, o que demonstra a relevância das atividades dessas atividades na estratégia corporativa.

Na GranBio, a equipe de pesquisa da subsidiária BioCelere foi montada e coordenada pelo Prof. Gonçalo Pereira (IB). O Centro de P\&D da BioCelere começou a funcionar em 2013 com 20 cientistas, incluindo 11 alunos de doutoramento da UNICAMP (FURTADO et al., 2020) e tinha como principal foco o aprimoramento genético de leveduras. A equipe de pesquisa era composta majoritariamente por ex-alunos da UNICAMP (notadamente de mestrado e doutorado), provenientes do Laboratório de Genômica e bioEnergia (LGE), coordenado pelo Prof. Gonçalo Pereira ${ }^{8}$.

Por sua vez, o estudo de caso da Bio Brasil Biotecnologia evidenciou que a capacidade de absorção da organização está centrada em um indivíduo, o gerente de produtos da empresa e egresso da UNICAMP. Na pesquisa de campo, evidenciou-se o papel de gatekeeper desempenhado por este profissional da Bio Brasil Biotecnologia na exploração das fontes externas de conhecimento e no estabelecimento e na gestão do relacionamento cooperativo com a universidade, posto que ele possui uma visão integrada entre a pesquisa acadêmica e as questões mercadológicas da empresa.

\footnotetext{
${ }^{7}$ A empresa realizou a transferência da tecnologia entre as equipes italiana e brasileira para o desenvolvimento do equipamento repetidor óptico submarino para a Google. Dessa forma, procurava replicar internamente a tecnologia desenvolvida na Itália.

8 Cabe notar que, conforme o ex-cientista chefe da GranBio, no contexto de dificuldades operacionais relacionadas ao desenvolvimento de tecnologia, ao atingimento da produção comercial da segunda geração de bioetanol e de problemas financeiros enfrentados pela empresa no período recente, as atividades de P\&D da subsidiária BioCelere, em Campinas, foram desativadas. Dessa forma, a GranBio passou a contar com a subsidiária norte-americana American Process Inc. (API), que havia desenvolvido plataformas de pré-tratamento de biomassa para produção de açúcar celulósico. O investimento nessa empresa incluiu biorrefinarias, além de um centro de P\&D e outros ativos. A GranBio adquiriu também o portfólio de propriedade intelectual das biorrefinarias, biocombustíveis, bioquímicos e campo de nanocelulose, de modo que detém atualmente mais de duas centenas de patentes (concedidas e depositadas) nos Estados Unidos (PESQUISA FAPESP: MARQUES, 2018),
} 
Ainda que seja detentora de patentes nacionais e internacionais referentes à tecnologia DAPI, a empresa não possui infraestrutura própria de $\mathrm{P} \& \mathrm{D}$ em suas unidades em Vinhedo e Anápolis. Todos os seus recursos humanos dedicados às atividades de $\mathrm{P} \& \mathrm{D}$ desenvolvem-nas no interior do IC da UNICAMP. Nesse caso, infere-se que a colaboração com a universidade ocorre na ausência de esforços internos de pesquisa na empresa.

Nas empresas dos KIBs, é importante observar, primeiramente, que a Griaule é uma empresa de base tecnológica cuja competência-foco é a P\&D de tecnologia em biometria (FLEURY e FLEURY, 2012). A atuação no mercado e as pesquisas universitárias são as fontes de competências tecnológicas e de inovação em produto para a empresa. Em sua estrutura organizacional a Griaule possui um departamento interno de P\&D, localizado na Cidade Universitária de Campinas, em uma unidade física à parte da sede da empresa, onde as atividades de P\&D são contínuas e eram conduzidas, quando da pesquisa de campo, por 20 funcionários (ou $80 \%$ dos recursos humanos da empresa). No que tange à formação acadêmica destes recursos humanos identifica-se o seguinte quadro: a) 1 pesquisador é pós-doutor; b) 1 é doutor; c) 1 é mestre; e d) os demais pesquisadores são graduados. Para os fins deste trabalho, é importante salientar que 19 desses 20 funcionários alocados na P\&D interna da Griaule eram ex-alunos da UNICAMP.

A estrutura que dá suporte aos empreendimentos inovadores do Grupo Movile é estabelecida sob dois princípios: vários segmentos inovativos funcionando simultaneamente e uma agressiva estratégia de marketing. Para o desenvolvimento de produtos (isto é, conteúdos e serviços móveis) e soluções, a Movile possui diversas áreas de tecnologia, que trabalham em sinergia. São elas: 1) áreas específicas que trabalham juntamente com as operadoras, criando produtos; 2) áreas internas de sistemas que auxiliam na administração das demais plataformas; 3) áreas de serviço de plataformas; 4) áreas de apps, que desenvolvem aplicativos tanto para Android, quanto para iOS. Cabe salientar que a inauguração recente de hubs em Porto Alegre, Recife e São Carlos relacionam-se à possibilidade de atração de profissionais de tecnologia altamente qualificados nessas regiões.

$\mathrm{Na}$ estrutura organizacional da QuintoAndar, times interdisciplinares de tecnologia e produto possuíam, no momento da pesquisa de campo, aproximadamente 400 pessoas, ou cerca de $36 \%$ dos seus funcionários. Sob o comando do CTO operam equipes de tecnologia, produtos, design e ciência de dados em dedicação exclusiva à resolução de problemas estratégicos. Tais equipes se encontravam estruturadas em 35 times interdisciplinares de produto e engenharia que trabalham de forma integrada. Nessas equipes há uma predominância de recursos humanos oriundos da ciência da computação, engenharia de computação e sistemas de informação. São, segundo o entrevistado, os chamados "computeiros".

É importante notar que embora a empresa tenha transferido sua sede para São Paulo no ano de 2015, recentemente reabriu um centro de engenharia e produto em Campinas, que trabalha de maneira integrada aos times de São Paulo. No escritório de tecnologia de Campinas trabalhavam cerca 30 pessoas (ou aproximadamente $8,0 \%$ do time de tecnologia e produto).

\subsection{A existência de vínculos (links) prévios entre as partes}

A literatura mostra que as atividades de ensino de universidades fomentam fluxos de recursos humanos e redes sociais e contatos informais (CAMPOS, 2010; COLOMBO e GARCIA, 2020; SALTER e MARTIN, 2001). Engenheiros e cientistas treinados em métodos e técnicas de pesquisa relevantes para a $P \& D$ da indústria transferem conhecimento para a indústria por meio desses mecanismos (SALTER e MARTIN, 2001). Campos (2010) salienta que desafiados por problemas aplicados, engenheiros e cientistas podem comunicá-los às suas redes universitárias. As consultas triviais são resolvidas informalmente, enquanto consultas elaboradas possam desencadear o desenvolvimento de pesquisas conjuntas, fomentando a dinâmica dos relacionamentos cooperativos U-E. Essas consultas são facilitadas pela existência de vínculos prévios entre as partes.

Os resultados da pesquisa indicam, de fato, que a existência de vínculos prévios entre os parceiros constituiu um importante fator direcionador do estabelecimento e da continuidade dos projetos colaborativos de empresas-filhas com a UNICAMP. Nesses casos, indivíduos-chave, particularmente ex-alunos de graduação e pós-graduação, que já possuíam contatos prévios com pesquisadores da universidade, tornaramse um importante fator para o estabelecimento e a gestão dos projetos colaborativos. Evidências mostram que os vínculos prévios de ex-alunos têm o efeito de retroalimentar os projetos de cooperação com a universidade. As contratações de ex-discentes desenvolvem, de modo cíclico, os relacionamentos cooperativos, particularmente quando se verifica também a proximidade geográfica entre os parceiros, visto que os pesquisadores da empresa comumente voltam a acessar o conhecimento de seus ex-professores e ex-colegas na universidade. Ademais, novas contratações de egressos de universidades específicas decorrem dos vínculos prévios estabelecidos entre as universidades e as empresas em relacionamentos cooperativos. 
A existência de vínculos prévios entre os parceiros foi um fator direcionador do estabelecimento e do desenvolvimento dos projetos de colaboração entre a UNICAMP e as empresas Griaule e Bio Brasil Biotecnologia, bem como das interações da Padtec com diferentes grupos de pesquisa da UNICAMP.

O caso da Griaule mostra, desde a sua fundação, uma forte vinculação com a UNICAMP, que se materializa sob duas formas: a) a condição de empresa graduada na incubadora da universidade (Incamp); e b) o número expressivo de ex-alunos de graduação e pós-graduação de engenharia de computação ( $95 \%$ dos pesquisadores da empresa), que se dedicam exclusivamente às atividades de $\mathrm{P} \& \mathrm{D}$ internas. Outro canal de interação entre a UNICAMP e a Griaule é a troca informal de informações entre seus pesquisadores e os professores da FEEC/UNICAMP.

Ademais da existência de um gerente de produto, que é ex-aluno da UNICAMP e que, conforme os entrevistados, realiza "a tradução do conhecimento científico na empresa", o vínculo da Bio Brasil Biotecnologia com a universidade remonta à empresa adquirida Immunoassay Indústria e Comércio, que, como indicado, era sócia controladora da ImmunoCamp Pesquisa e Desenvolvimento de Tecnologia, organização que esteve incubada na Incamp, ; inclusive um dos pesquisadores da universidade, diretamente envolvido com o desenvolvimento da tecnologia DAPI, foi assessor científico da Immunoassay.

Parcela significativa dos relacionamentos cooperativos da Padtec com a UNICAMP também indicam a importância dos vínculos prévios, que retroalimentam os projetos colaborativos no tempo. Na condição de spin-off, a Padtec possui vínculos estreitos com o $\mathrm{CPqD}$, fundação com a qual realiza os trabalhos de desenvolvimento tecnológico com maiores complexidade e risco. Ademais, desde a sua fundação, a empresa e pesquisadores do IFGW e da FEEC da UNICAMP possuem fortes vínculos cooperativos voltados ao desenvolvimento de tecnologias na área óptica e fotônica. A Padtec teve como cofundadores dois ex-alunos da UNICAMP (de graduação e pós-graduação) e parcela significativa dos profissionais alocados na P\&D interna são egressos da UNICAMP (cerca de 50\%), o que demonstra a importância dos vínculos prévios para a dinâmica dos projetos colaborativos com a universidade e para a troca informal de informações.

Da mesma forma, a forte vinculação de pesquisadores da BioCelere com o Laboratório de Genômica e bioEnergia (LGE) da UNICAMP possibilitou que diferentes canais de relacionamentos U-E se fizessem presentes ao longo do tempo, quais sejam, pesquisa científica, transferência de tecnologia desenvolvida pelo parceiro, contratação de recém-graduados e pós-graduados e troca informal de informações.

Por sua vez, embora a QuintoAndar e Movile ressaltem em suas políticas de recursos humanos a importância da promoção da diversidade de seus colaboradores, essas empresas absorvem vários ex-alunos da UNICAMP em suas unidades. Segundo os entrevistados, particularmente os postos de trabalho gerados na Região Metropolitana de Campinas, que requerem elevada qualificada da mão-de-obra, são ocupados, em grande medida, por ex-alunos da própria universidade.

É importante notar que as empresas Griaule, Padtec, GranBio, QuintoAndar e Movile evidenciaram que já desenvolveram capacitações para a busca de conhecimento externo (NELSON; WINTER, 2005; COHEN; LEVINTHAL, 1990), em razão de serem capazes de identificar o conhecimento externo relevante e estabelecer vínculos cooperativos, mesmo quando não há vínculos prévios entre os agentes.

\subsection{A proximidade geográfica}

A proximidade geográfica entre as empresas investigadas e a UNICAMP constitui um importante fator direcionador da maior parte dos seus relacionamentos, visto que essa proximidade facilita e estimula os processos de aprendizado interativo, o que se traduz na intensificação das formas de transferência do conhecimento gerado na universidade. Os resultados alcançados mostram a importância de três canais de transferência de conhecimento nesses relacionamentos: troca informal de informações por meio de interações face-a-face; pesquisa conjunta; e pessoal contratado com graduação ou pós-graduação. As interações pessoais diretas desenvolvem capital social, tal como confiança, "linguagem" conjunta e cultura de pesquisa conjunta (SCHARTINGER et al., 2002; GARCIA et al., 2011).

A Griaule localiza-se a cerca de $5 \mathrm{~km}$ da FEEC. A proximidade geográfica entre a empresa e a universidade constitui um importante direcionador da cooperação U-E, por facilitar as trocas informais de informação, um dos principais canais de transferência de conhecimento U-E presentes neste caso. De maneira similar, a proximidade geográfica entre a Bio Brasil Biotecnologia - unidade Vinhedo - e o IC/UNICAMP (23 $\mathrm{km}$ ) é um importante fator direcionador do relacionamento cooperativo U-E, pois possibilita que o gerente de produto (e gatekeeper do conhecimento) mantenha intensas e frequentes trocas informais de informação com os pesquisadores do IC/UNICAMP por meio de encontros semanais.

A Padtec mantém alguns relacionamentos cooperativos em situação de proximidade geográfica, com contatos frequentes e trocas informais de informação: 1) o CPqD (a uma distância de cerca de 350 metros) e; 
2) na UNICAMP, a FEEC e o IFGW (a $2,5 \mathrm{~km}$ ). A maioria dos projetos de colaboração da Padtec de médio prazo, desenvolvedores de um novo produto, é realizada juntamente com o CPqD. De modo geral, os relacionamentos cooperativos da Padtec com a UNICAMP compreendem projetos de pesquisa aplicada, voltados ao desenvolvimento de produtos. Ademais, a universidade é comumente buscada pela empresa para a solução de problemas, situações em que a auxilia com equipamentos e recursos humanos.

Da mesma forma, a proximidade entre a subsidiária da GranBio - BioCelere - e o IB/UNICAMP $(9,29$ $\mathrm{km}$ ) facilitou o estabelecimento dos relacionamentos cooperativos de pesquisa científica, transferência de tecnologia e troca informal de informações entre as partes. Ademais, a proximidade com a universidade possibilitou que o cientista-chefe da empresa mantivesse atividades de docência e pesquisa na UNICAMP, fomentando os fluxos bidirecionais de conhecimento.

Vale notar também que a proximidade entre a sede da QuintoAndar $(106 \mathrm{~km})$ e do escritório de tecnologia de Campinas em relação ao IC/UNICAMP facilitam a contratação de recursos humanos e criam as condições para que se estabeleçam trocas informais de interação entre as partes. O mesmo se verifica em relação à sede da Movile em Campinas em relação ao IC (10,5Km).

\subsection{A proximidade cognitiva}

Os estudos de caso evidenciam que a proximidade cognitiva entre o pessoal de P\&D e de engenharia/tecnologia das empresas investigadas e os pesquisadores da UNICAMP constitui um importante fator direcionador da dinâmica da cooperação U-E. Agentes com elevada capacidade cognitiva possuem uma base comum de conhecimento e expertise, o que facilita a comunicação e fomenta processos de aprendizado interativo. O capital social constituído por meio das interações pessoais entre os agentes nas firmas e na universidade facilita a construção de laços de confiança entre eles (COLOMBO e GARCIA, 2020; SCHARTINGER et al., 2002).

No caso da Griaule, a origem da empresa, na incubadora da UNICAMP, e as características de seu pessoal de pesquisa, cuja qualificação em engenharia foi realizada na FEEC, evidencia que a organização não precisa dedicar muitos recursos e tempo à construção de vínculos com a universidade, visto que esses vínculos foram construídos a partir de sua constituição e da composição de seus recursos humanos. Situação similar ocorreu entre os pesquisadores da BioCelere e a equipe do Laboratório de Genômica e bioEnergia (LGE) da UNICAMP.

Na Bio Brasil Biotecnologia, a formação acadêmica do gerente de produtos ocorreu na graduação em Biologia e mestrado em Parasitologia no IB/UNICAMP, o que promoveu a criação de laços comuns entre os o gatekeeper do conhecimento na empresa e os pesquisadores da universidade, denotando a forte proximidade cognitiva entre eles. Essa proximidade também se verifica em relação aos recursos humanos que desenvolvem as atividades de P\&D da empresa no IC/UNICAMP e os pesquisadores da universidade.

Em relação à Padtec, o compartilhamento de uma base de conhecimento comum pelos profissionais alocados na $\mathrm{P} \& \mathrm{D}$ interna e pelos engenheiros do $\mathrm{CPqD}$, bem como pelos pesquisadores da FEEC e do IFGW da UNICAMP, propicia que, na dinâmica dos relacionamentos cooperativos, sejam desenvolvidos projetos conjuntos de pesquisa e ocorram trocas informais de conhecimento entre as partes sobre questões específicas dos desenvolvimentos da empresa. A participação de funcionários da empresa nos programas de pós-graduação da FEEC e no IFGW retroalimenta o estabelecimento dos relacionamentos cooperativos ao longo do tempo. Nos casos da QuintoAndar e da Movile, o compartilhamento de uma base de conhecimento comum entre uma parcela de seus recursos humanos em atividades de tecnologia e produto criam as condições requeridas para que os mesmos voltem a acessar o conhecimento de seus ex-docentes no IC (ou na FEEC).

\subsection{0 acesso ao financiamento público e a concessão de benefícios fiscais no âmbito da Lei de Informática}

Primeiramente, é importante notar que algumas empresas investigadas - Padtec, Griaule, Bio Brasil Biotecnologia e GranBio - já foram beneficiárias de alguns programas públicos de financiamento a atividades inovativas de agências, tais como FINEP - Subvenção e linhas de financiamento, BNDES - Subvenção, CNPq - Bolsas RHAE Pesquisador na Empresa e a agência estadual FAPESP - PIPE e PITE. Em segundo lugar, os estudos de caso mostram que o financiamento público desempenhou um duplo papel como direcionador das cooperações U-E dessas empresas com a UNICAMP. Por um lado, o financiamento público foi o catalizador de alguns dos projetos de colaboração das empresas com a universidade parceira, auxiliando-as a transporem a escassez interna de capital para esse fim, por meio do uso de recursos financeiros das agências de fomento e do compartilhamento de outros recursos, como pessoal e laboratórios, entre as empresas e as universidades 
envolvidas. Além disso, o financiamento público constituiu um fator direcionador fundamental de muitos desses projetos cooperativos, visto que foram compostos por recursos, financeiros e humanos (que as empresas não possuíam) e elevada complexidade e riscos.

Entre os casos analisados, há ao menos dois exemplos bastante precisos desse duplo papel do financiamento público. O primeiro é o desenvolvimento da nova tecnologia de exame parasitológico de TF Test e TF-Test Modified na empresa Bio Brasil Biotecnologia, em que a ausência do esquema de financiamento público da FAPESP inviabilizaria o investimento necessário para o desenvolvimento da tecnologia. O segundo é caso da Padtec, em que o financiamento do PITE/FAPESP na última década foi fundamental para o estabelecimento de uma nova cooperação com a FEEC, voltada para o apoio à pesquisa em telecomunicações e comunicação óptica, ao desenvolvimento de produtos mais próximos da fronteira de conhecimento e à formação de recursos humanos.

\section{CONSIDERAÇÕES FINAIS}

Este trabalho traz alguns elementos para a elucidação de importantes características dos relacionamentos entre spin-offs acadêmicas, startups e universidades e para o entendimento dos fatores direcionadores (drivers) da formação e da dinâmica da interação U-E. A pesquisa de campo permitiu identificar que são diversas as variáveis que influenciam a propensão de empresas-filhas da UNICAMP a cooperarem com a universidade ao longo do tempo.

Primeiramente, os estudos de casos demonstraram que os setores de atividade econômica e a capacidade de absorção da firma são fatores determinantes do desenvolvimento dos relacionamentos cooperativos U-E. O setor de atividade é um importante conformador dos canais utilizados nos processos de transferência de conhecimento entre a universidade e as empresas. As empresas-filhas dos setores industriais baseados em ciência e intensivos em P\&D, fornecedor especializado e dominado pelos fornecedores mantiveram relacionamentos cooperativos de longo prazo com a UNICAMP baseados principalmente nos desenvolvimentos conjuntos, na transferência de tecnologia e na contratação de recursos humanos, isto é, exalunos graduação e pós-graduação. Já as empresas dos setores de serviços contam com relacionamentos com a universidade calcados prioritariamente na contratação de ex-alunos.

A pesquisa de campo evidenciou que as atividades internas de $\mathrm{P} \& \mathrm{D}$ ou desenvolvimento/tecnologia (formais e contínuas) e a qualificação da mão de obra alocada nessas atividades favorecem o desenvolvimento das capacidades absortivas de cinco empresas-filhas pesquisadas. Tais condições propiciam as capacitações para que as empresas possam, em uma perspectiva temporal, explorar as fontes externas de conhecimento, acompanhar o desenvolvimento tecnológico em seus setores de atuação e a gerir suas cooperações com a UNICAMP, expressando a existência de capacidade de absorção.

Cabe a exceção de uma pequena empresa investigada, que, não possuindo estrutura própria de $\mathrm{P} \& \mathrm{D}$, utiliza a infraestrutura de pesquisa da universidade quanto a laboratórios e pessoal em dedicação exclusiva às atividades de P\&D. Nessa empresa, foi determinante para o estabelecimento e o desenvolvimento da cooperação U-E a existência de vínculos prévios entre as partes, através da contratação de um egresso da universidade, que exerce o papel de gatekeeper do conhecimento.

Vale salientar que nos relacionamentos cooperativos investigados, indivíduos-chave, que já possuíam contatos prévios com pesquisadores da universidade, constituíram um importante fator para a formação e a continuidade da cooperação U-E. Essa vinculação ficou evidente, primeiramente, na perspectiva dos cofundadores das empresas-filhas. Adicionalmente, recursos humanos, na condição de ex-alunos de graduação e pós-graduação, tornaram-se um importante driver da cooperação com a universidade em todas as empresasfilhas investigadas. Tais recursos humanos fazem uso do conhecimento e das habilidades aprendidas na universidade e retroalimentam os seus relacionamentos cooperativos ao longo do tempo. Tais vinculações são fortemente direcionadas pelas proximidades geográfica e cognitiva entre os agentes.

A proximidade geográfica entre as organizações viabiliza a transferência de conhecimento das universidades por meio de três dos principais canais de transferência de conhecimento identificados nos relacionamentos cooperativos investigados, quais sejam, a troca informal de informações face a face, a pesquisa conjunta e a transferência de tecnologia. As evidências dos estudos de caso mostram também que firmas com baixa capacidade de absorção dependem mais da proximidade geográfica com universidades, $o$ que corrobora estudos prévios (GARCIA et al., 2015). Em contraste, as firmas com elevada capacidade de absorção possuem uma maior gama de parceiros acadêmicos potenciais, as quais são capazes de buscar (e encontrar) parceiros acadêmicos geograficamente mais distantes, o que reforça o papel da capacidade de absorção como um direcionador importante da colaboração das empresas com a universidade.

Os seis estudos de caso evidenciam ainda que a existência de proximidade cognitiva entre os recursos 
humanos das empresas-filhas e os pesquisadores da universidade, por meio do compartilhamento de uma base comum de conhecimento, é um importante fator direcionador da dinâmica dos relacionamentos cooperativos com a UNICAMP.

É importante notar também que o financiamento público exerceu, por um lado, o papel de catalisador de alguns dos relacionamentos cooperativos com a UNICAMP, auxiliando essas empresas-filhas a transpor a escassez interna de recursos pelo compartilhamento de recursos com as agências. Por outro lado, o financiamento público constituiu um fator direcionador fundamental do estabelecimento de algumas cooperações investigadas, as quais envolviam maiores complexidade e risco. Cabe salientar ainda que a disponibilidade do financiamento público possibilitou a continuidade dos relacionamentos cooperativos ao longo do tempo.

\title{
DRIVING FACTORS OF THE UNIVERSITY-INDUSTRY RELATIONSHIPS: MULTIPLE CASE STUDIES OF UNICAMP-RELATED FIRMS
}

\begin{abstract}
:
This work investigates the driving factors of the interaction of UNICAMP-related firms with the university. To this end, it explores the results of six exploratory case studies of UNICAMP-related firms 'cooperative relationships with the university. Structural and behavioral characteristics of the firms investigated, their cooperative relationships with UNICAMP and the S\&T\&I policy that are conducive to the development of cooperation between the parties are investigated. The results show that there are several variables that influence the propensity of these firms to cooperate with UNICAMP throughout the time. The firm's absorptive capacity, the existence of previous links and the geographic and cognitive proximity between the parties are important driving factors of the establishment and development of the investigated firms' cooperation with the university. The case studies also show the importance of access to public funding for cooperation, especially when they include greater complexity and risk.
\end{abstract}

Keywords: driving factors; university-industry-relationships; UNICAMP-related firms

\section{Referências bibliográficas}

ALBUQUERQUE, E. SILVA, L.; POVOA, L. Diferenciação intersetorial na interação entre empresas e universidades no Brasil. São Paulo em Perspectiva, v. 19, n. 1, p. 95-104, jan./mar. 2005.

ALLEN, T. J. Managing the Flows of Technology: Technology Transfer and the Dissemination of Technological Information within the R\&D Organization, MIT Press. Cambridge, MA.: 1977.

ALVES FILHO, M. "Olho eletrônico" obtém dectecção automática de parasitos intestinais. Jornal da Unicamp, 11 a 17 junho de 2007 , p. 5.

ANGELI, J., VARRICHIO, P. Gestão da inovação em etanol 2G: um estudo de caso em uma empresa brasileira.

Anais da ALTEC 2017, ALTEC. Ciudad de Mexico: 2017.

ARZA, V.; DE FUENTES, C.; DUTRENIT, G.; VAZQUEZ, C. Channels and benefits of interactions between public research organizations and industry: comparing country cases in Africa, Asia, and Latin America; In ALBUQUERQUE, E.; SUZIGAN, W.; KRUSS, G.; LEE, K. (Eds) Developing National Systems of Innovation: University-Industry Interactions in the Global South, Edward Elgar Publishing, Cheltenham/Ottawa: 2015, p. 164-193.

ARBIX, G.; CONSONI, F. Inovar para transformar a Universidade brasileira. Revista Brasileira de Ciências Sociais, v. 26, n. 77, p. 205-251, out. 2011.

ARUNDEL, A.; GEUNA, A. Proximity and the use of public science by innovative European firms. Economics of Innovation and New Technology, v. 13, n. 6, p. 559-580, 2004.

BALDONI, L. A UNICAMP como ator principal na construção de um parque cientifico e tecnológico. International Journal of Innovation, v. 2, n. 2, p. 118-127, jul/dec. 2014.

BERCOVITZ, J.; FELDMANN, M. Entpreprenerial Universities and Technology Transfer: a Conceptual Framework for Understanding Knowledge-Based Economic Development. Journal of Technology Transfer, v. 31, p. $175-188,2006$.

BASTOS, C.; BRITTO, J. Inovação e geração de conhecimento científico e tecnológico no Brasil: uma análise dos dados de cooperação da Pintec segundo porte e origem de capital. Revista Brasileira de Inovação, v. 
16, n. 1, p. 35-62, 2017.

BOSCHMA, R. Proximity and innovation: a critical survey. Regional Studies, v. 39, n. 1, p. 61-74, 2005.

BROSTRÖM, A. Working with distant researchers-Distance and content in university-industry interaction.

Research Policy, v. 39, n. 10, p.1311-1320, 2010.

BRITO, L. A.; CARVALHO, L. Movile: sustaining an innivative culture on a global scale. In: OZOÑO, S.; ICHIJO, K. (Eds) Business Despite Borders: companies in the age of populist anti-globalization, Palgrave, MacMillan. 1. ed. Cham: 2018, p. 89-104.

BRUNEEL, J.; D'ESTE, P.; SALTER, A. Investigating the factors that diminish the barriers to universityindustry collaboration. Research Policy, v. 39, p. 858-868, 2010.

CALIL NETO, A.; GUIMARAES, M.J.; FREIRE, E. Business models for commercial scale second-generation bioethanol production. Journal of Cleaner Production, v. 184, p. 168-178, 2018.

CAMPOS, A. A review of the influence of long-term patterns in research and technological development (R\&D) formalisation on university-industry links. Revista Brasileira de Inovação, v. 9, p. 379-410, 2010.

CAMPOS, B.; RUIZ, A. Padrões Setoriais de Inovação na Indústria Brasileira. Revista Brasileira de Inovação, v. 8, n. 1, p.167-210, 2009.

CARDAMONE, P.; PUPO, V. R\&D cooperation between firms and universities: some evidence in five European countries. Working Paper n. 01-15. Università Della Calabria, 2015

COHEN, W.; NELSON, R.; WALSH, J. Links and impacts: the influence of public research on industrial R\&D.

Management Science, v. 48, n. 1, p, 1-23, 2002.

COHEN, W.; LEVINTHAL, D. Absorptive Capacity: A New Perspective on Learning and Innovation. Administrative Science Quarterly, v. 35, n. 1, p. 128-1S2, 1990.

COLOMBO, D.; GARCIA, R. The role of academic relations of former graduate students in university-firm collaboration: evidence from Brazil. Texto para Discussão (Campinas), 2020.

CONSOLI, D.; ELCHE-HORTELANO, D. Variety in the knowledge base of Knowledge Intensive Business Services. Research Policy, v. 39, p. 1303-1310, 2010.

CYERT, R.; GOODMAN, P. Creating effective university-industry alliances: an organizational learning perspective. Organizational Dynamics, v. 25, n. 4, p. 45-57, 1997.

DE FUENTES, C.; DUTRENIT, G. Best channels of academia-industry interaction for long-term benefit. Research Policy, v. 41, n. 9, p. 1666-1682, 2012.

D 'ESTE, P.; PATEL, P. University-industry linkages in the UK: What are the factors underlying the variety of interactions with industry? Research Policy, v. 36, n. 9, p. 1295-1313, 2007.

D'ESTE, P., GUY, F., IAMMARINO, S. Shaping the formation of university-industry research collaborations: what type of proximity does really matter? Journal of Economic Geography, v. 13, n. 4, p. 537-558, 2013. DREJER, I.; ØSTERGAARD, C. Exploring determinants of firms' collaboration with specific universities: Employeedriven relations and geographical proximity. Regional Studies, Published online: 09 Mar 2017.

DI GREGORIO, D; SHANE, S.; Why do some universities generate more start-ups than others? Research Policy, v. 32, p. 209-227, 2003.

ETZKOWITZ, H.; WEBSTER, A.; GEBHARDT, C.; TERRA, B. The future of the university and the university of the future: evolution of ivory tower to entrepreneurial paradigm. Research Policy, v. 29, p. 313-330, 2000. FLEURY, A.; FLEURY, M. T. Multinacionais brasileiras: competências para a internacionalização, FGV. $1^{\circ}$. ed. Rio de Janeiro: 2012.

FONTANA, R.; GEUNA, A.; MATT, M. 2003. Firm size and openness: the driving forces of universityindustry collaboration. SPRU Working Paper Series, n.103, Science and Technology Policy Research, University of Sussex, 2003.

FREIRE, C. E. T. Um estudo sobre os serviços intensivos em conhecimento no Brasil. In: DE NEGRI, J. A.; KUBOTA, L. C. (Org). Estrutura e dinâmica do setor de serviços no Brasil, IPEA. Brasília: 2006.

FURTADO, A.; HEKKERT, M.; NEGRO, S. Of actors, functions, and fuels: Exploring a second generation etanol transition from a technological innovation systems perspective in Brazil. Energy Research \& Social Science, v. 70, 2020. Available online 04 August 2020.

GARCIA, R. Geografia da inovação. In: RAPINI, M.; SILVA, L.; ALBUQUERQUE, E. (Orgs) Economia da ciência, tecnologia e inovação: fundamentos teóricos e a economia global, Prismas. Curitiba: 2017, p. 241-285.

GARCIA, R.; ARAUJO, V. MASCARINI, S.; SANTOS, E. Os efeitos da proximidade geográfica para o estímulo da interação universidade-empresa. Revista de Economia, v. 37, n. Especial, p. 307-330, 2011.

GARCIA, R.; ARAUJO. V.; MASCARINI, S. The role of geographical proximity for university-industry linkages in Brazil: an empirical analysis. Australasian Journal of Regional Studies, v. 19, p. 433-455, 2013.

GARCIA, R; ARAUJO, V.; MASCARINI, S; SANTOS, E.; COSTA, A. Looking at both sides: how specific characteristics of academic research groups and firms affect the geographical distance of university-industry linkages. Regional Studies, Regional Science, v. 2, n. 1, p. 518-534, 12015.

GARCIA, R.; ARAUJO, V.; MASCARINI, S. ; SANTOS, E.; COSTA, A. An analysis of the relation between geographical and cognitive proximity in university-industry linkages. In: Anais do 44 Encontro Nacional de 
Economia, ANPEC. Foz do Iguaçu: 2016.

GARCIA, R.; ARAUJO, V.; MASCARINI, S; SANTOS, E.; COSTA, A. Is cognitive proximity a driver of geographical distance of university-industry collaboration? Area Development and Policy, v. 3, p. 1-19, 2018.

GARCIA, R.; ARAUJO, V.; MASCARINI, S.; SANTOS, E.; COSTA, A. How long-term university-industry collaboration shapes the academic productivity of research groups. Innovation: Management, Policy \& Practice, v. 21, p. 1-15, 2019.

GASPAROTO, M.; FISCHER, B. Redes organizacionais, universidade e o ecossistema de empreendedorismo: um estudo utilizando análise de redes sociais. Anais do XI Encontro de Estudos sobre Empreendedorismo e Gestão de Pequenas Empresas, ANEGEPE. Belo Horizonte: 2020.

GEUNA, A.; MUSCIO, A. The governance of university knowledge transfer: a critical review of the literature. Minerva, v. 47, p. 93-114, 2009.

GOMES, J.; HOSHINO-SHIMIZU, S.; FALCAO, A. Recentes avanços tecnológicos no exame parasitológico de fezes. BIO FARMA - Revista Técnico-Científica de Farmácia, Bioquímica e Análises Clínicas e Toxicológicas, v. 3, n. 6, p. 44-53, 2008.

GUERRERO, M.; CUNNINGHAM, J. A. URBANO, D. Economic impact of entrepreneurial universities'activities: an exploratory study of the United Kingdom. Research Policy, v. 44, p. 748-764, 2015.

HANEL, P.; ST-PIERRE, M. Industry-university collaborations by Canadian manufacturing firms. Journal of Technology Transfer, v.31, p. 485-499, 2006.

HIPP, C.; GRUPP, H. Innovation in the service sector: The demand for service-specific innovation measurement concepts and typologies. Research Policy, v. . 34, p. 517-535, 2005.

INGLEZ, M.; ANDRADE, N.; ULTREMARE, F.; MORI, M. O perfil empreendedor dos egressos da UNICAMP. In: Anais da 26a Conferência Anprotec de Empreendedorismo e Ambientes de Inovação, Anprotec. Fortaleza: 2016.

INOVA UNICAMP. Relatório de Atividades da Agência de Inovação da UNICAMP. Campinas: Inova UNICAMP, 2019.

INOVA UNICAMP. Relatório de Atividades 2011. Campinas: Inova UNICAMP, 2011.

KLEVORICK, A.; LEVIN, R.; NELSON, R.; WINTER, S. On the sources and significance of inter-industry differences in technological opportunities. Research Policy, v. 24, p. 185-205, 1995.

KNOBEN, J.; OERLEMANS, L.A. Proximity and inter-organizational collaboration: A literature review. International Journal of Management Reviews, v. 8, n. 2, p. 71-89, 2006.

KUBOTA, L. C. As Kibs e a inovação tecnológica das firmas de serviços. Economia e Sociedade, v. 18 n. 2 , p. 349-369, ago. 2009.

LAAGE-HELLMAN, J.; LIND, F.; ÖBERG, C.; SHIH, T. Interactions between university spin-offs and academia: a dynamic perspective. Journal of Business \& Industrial Marketing, v. 35, n. 12, p. 1941-1955, 2020.

LAURSEN, K.; SALTER, A. Searching high and low: what types of firms use universities as a source of innovation? Research Policy, v. 33, n. 8, p. 1201-1215, 2004.

LAURSEN, K.; REICHSTEIN, T.; SALTERS, A. Exploring the effect of Geographical Proximity and University Quality on University-Industry Collaboration in the United Kingdom. Regional Studies, v. 45, n. 4, p. 507523, 2011.

LAVCA Inside QuintoAndar's ascendancy in Brazilian Real Estate Tech: interview with CTO Andre Penha, 22/04/2019. LAVCA The Association for Private Capital Investment in LatinAmerica. Disponível em https://lavca.org/2019/04/22/inside-quintoandars-ascendancy-in-brazilian-real-estate-tech-interview-with-

cto-andre-penha/ Acesso em 15/02/2020.

LEMOS, P. Universidades e ecossistemas de empreendedorismo: a gestão orientada por ecossistemas e o empreendedorismo da UNICAMP, Editora da UNICAMP. Campinas: 2012.

LINK, A.; SCOTT, J. Opening the ivory tower's door: An analysis of the determinants of the formation of U.S. university spin-off companies. Research Policy, v. 34, p. 1106-1112, 2005.

LOCKETT, A.; WRIGHT, M. Resources, capabilities, risk capital and the creation of university spin-out companies. Research Policy, v. 34, p. 1043-1057, 2005.

MANSFIELD, E.; LEE, J.-Y. The modern university: contributor to industrial innovation and recipient of industrial R\&D support. Research Policy, v. 25, n. 7, p. 1047-1058, 1996.

MARQUES, F. Obstáculos no caminho. Pesquisa FAPESP, 268, p. 58-63, junho de 2018.

MILES, I. Research and development (R\&D) beyond manufacturing: the strange case of services R\&D. R\&D Management, v. 37, n. 3, p.249-268 2007.

MOHNEN, P.; HOAREAU, C. What type of enterprise forges close links with universities and government labs? Evidence from CIS 2. Managerial and Decision Economics, v. 24, n. 2-3, p. 133-145, 2003.

MORA-VALENTIN, E M..; MONTORO-SANCHEZ, A.; GUERRAS-MARTIN, L. A. Determining factors in the success of R\&D cooperative agreements between firms and research organizations. Research Policy, v. 33, n. 1, p. 17-40, 2004.

MORGAN, J.; ZIEBELMAN, P.; FOSTER, G.; MATSUSHITA, K. Movile: Going global - is sylicon valley te next 
stop? Stanford Graduate School of Business, Case: E-539A, Harvard Business Publishing, February 2015. MOTOYAMA, Y. Long-term collaboration between university and industry: A case study of nanotechnology development in Japan. Technology in Society, v. 36, p. 39-51, 2014.

MOTOYAMA, Y.; MALIZIA, E. Demand pull or supply push? Metro-level analysis of start-ups in the United States. Regional Studies, Regional Science, 4(1), p. 232-246, 2017.

MOVILE E-book Grupo Movile. Movile, 2019. Disponível em <https://materiais.movile.com/grupo-movile>. Acesso em 01/03/2020.

MOWERY, D. C.; SAMPAT, B. N. Universities in national innovation systems. In: FAGERBERG, J.; MOWERY, D. C.; NELSON, R. R. (Orgs.) The Oxford handbook of innovation, Oxford University Press. Oxford:, 2005, p. 209-239.

MUSCIO, A.; QUAGLIONE, D.; RAMACIOTTI, L. The effects of university rules on spinoff creation: The case ofacademia in Italy. Research Policy, v. 45, p. 1386-1396, 2016.

NELSON, R.; WINTER, S. Uma Teoria Evolucionária da Mudança Econômica, Editora da UNICAMP . Campinas: 2005.

NOWAK, M. J; GRANTHAM, C.E. The virtual incubator: managing human capital in the software industry. Research Policy, v. 29, n. 2, p.125-134, 2000.

PADTEC. Relatório de Administração. Campinas:Padtec, 2017.

PLAIS, H. L. Os desafios da internacionalização de uma startup brasileira: o caso da Movile. Dissertação (Mestrado). São Paulo: Insper Instituto de Ensino e Pesquisa, 2016.

OLIVEIRA, V.; GARCIA, R.; BACIC, M. J. Fatores direcionadores da cooperação de pequenas e médias empresas com a universidade: evidências a partir de quatro estudos de caso. Revista Econômica, v. 20, n. 2, p. 85-106, 2018.

RAPINI, M.; OLIVEIRA, V.; SILVA NETO, F. A natureza do financiamento influencia na interação universidadeempresa no Brasil? Revista Brasileira de Inovação, v. 13, n. 1, p. 77-108, janeiro/junho 2014.

RASIAH, R.; GOVINDARAJU, C University-industry R\&D collaboration in the automotive, biotechnology and electronic firms in Malaysia. Seoul Journal of Economics, v. 22, n. 4, p. 530-550, 2009.

RIBEIRO, F.; PIMENTEL, J. E. Empresas born globals brasileiras: a influência do perfil do empreendedor e da localização geográfica. Cadernos de Administração (Revista da Faculdade de Administração da FEA PUC SP), v. 5, n. 1, p. 1-24, 2011.

ROSA, A.; RUFFONI, J.; GARCIA, R. Capacidade de absorção e desempenho inovativo: uma análise para as firmas interativas com grupos de pesquisa universitários das áreas das engenharias do Rio Grande do Sul.

Revista Brasileira de Economia de Empresas, v. 18, n. 1, p. 71-91, 2018.

SALTER, A.; MARTIN, B. The economic benefits of publicly funded basic research: a critical review Research Policy, v. 30, p. 509-532, 2001.

SANTORO, M.; CHAKRABARTI, A. Firm size and technology centrality in industry-university interactions. Research Policy, v. 31, p.1163-1180, 2002.

SCHAEFFER, P., FISCHER, B., QUEIROZ, S. (2018). Beyond education: the role of research universities in innovation ecosystems. Foresight and STI Governance, v. 12, n. 2, p. 50-61, 2018.

SCHARTINGER, D.; SHIBANY, A.; GASSLER, H. Interactive relations between universities and firms: empirical evidence for Austria. Journal of Technology Transfer, 26, p.255-268, 2001

SCHARTINGER, D.; RAMMER, C.; FISCHER, M.; FRÖHLICH, J. Knowledge interactions between universities and industry in Austria: sectoral patterns and determinants. Research Policy, v. 31, 303-328, 2002.

SOHN, W.; KENNEY, M. Universities, clusters and innovation systems: the case of Seul. World Development, v. 35, n. 6, p. 991-1004, 2007.

TREIBICH, T.; KONRAD, K.; TRUFFER, B. A dynamic view on interactions between academic spin-offs and their parent organizations. Technovation, v. 33, n. 12, p. 450-462, 2013.

TEIXEIRA, A. L.; ROSA, A.; RUFFONI, J.; RAPINI, M. Dimensões da capacidade de absorção, qualificação da mão de obra, P\&D e desempenho inovativo. Revista Brasileira de Inovação, v. 15, n. 1, p. 139-164, 2016. TETHER, B. Who co-operates for innovation, and why. An empirical analysis. Research Policy, v. 31, p. 947967, 2002.

TORRES, A.; DUTRÉNIT, G.; SAMPEDRO, J. L.; BECERRA, N. What are the factors driving university-industry linkages in latecomer firms: evidence from Mexico Science and Public Policy, v. 38, n. 1, p. 31-42, 2011. URBANO, D.; GUERRERO, M. Entrepreneurial Universities: Socioeconomic Impacts of Academic Entrepreneurship in a European Region. Economic Development Quarterly, v. 27, n. 1 p. 40-55, 2013.

van STIJN, N., van RIJNSOEVER, F.; van VEELEN, M. Exploring the motives and practices of university-startup interaction: evidence from route 128. The Journal of Technology Transfer, v. 43, n. 3, p. $674-713$, 2018. 